ARTÍCULO

\title{
LA COFRADÍA DE LA VIRGEN DE GUADALUPE FUNDADA POR INDIOS EN EL SANTUARIO DEL TEPEYAC, 1678-1800
}

\author{
THE BROTHERHOOD OF THE VIRGIN OF GUADALUPE FOUNDED \\ BY INDIANS AT THE SANCTUARY OF TEPEYAC, 1678-1800
}

\section{Juan Javier OrTIZ RODEA}

Universidad Autónoma del Estado de México

jortizrod@outlook.es

ORCID: 0000-0001-7448-6283

\section{Resumen}

El presente artículo tiene el propósito de analizar a la Cofradía de la Virgen de Guadalupe, fundada por los indios del santuario del Tepeyac, en su carácter de institución corporativa, de 1678 a 1800. Esta asociación tuvo la finalidad de integrar y organizar a los indios de la jurisdicción del pueblo de Guadalupe, no sólo los congregó para la realización de los oficios litúrgicos, sino que también les dio la posibilidad de ocupar algún cargo en el gobierno civil.

Palabras clave: Cofradía de la Virgen de Guadalupe; santuario del Tepeyac; pueblo de Guadalupe; indios; corporativismo eclesiástico; oficios litúrgicos.

\begin{abstract}
The purpose of this article is to analyze the Brotherhood of the Virgin of Guadalupe, founded by the Indians of the Sanctuary of Tepeyac, in its capacity as corporate institution from 1678 to 1800 . This association had the intention of integrating and organizing the Indians jurisdiction of the town of Guadalupe that not only congregated them for the liturgical celebrations, but also gave them the possibility to get a position in the civil government.
\end{abstract}

Keywords: Brotherhood of the Virgin of Guadalupe; Sanctuary of Tepeyac; Town of Guadalupe; Indians; Church corporatism; liturgical celebrations.

\section{Información del artículo}

Recibido: 3 de junio de 2019.

Aceptado: 19 de agosto de 2019.

DOI: 10.22201/iih.24486922e.2020.62.69896

\section{Introducción}

Durante la segunda mitad del siglo xvi la Iglesia en la Nueva España asumió como principales tareas integrar y unificar a todos los sectores de la población alrededor de la fe católica, para lo cual las autoridades eclesiásticas tuvieron que tomar en cuenta prácticas de cohesión social, como la devoción 
a las imágenes milagrosas de Cristo, de la virgen María y de los santos, la veneración de las reliquias, la celebración de las fiestas, el fomento de las peregrinaciones y procesiones, así como la organización de los individuos a partir de las corporaciones para animar con mayor fuerza el culto divino en el Nuevo Mundo.

De manera que el instrumento utilizado por la Corona española y el clero para disciplinar, articular y agrupar a la sociedad novohispana fue el corporativismo eclesiástico. Lara Mancuso lo define como un conjunto de valores, reglas, ceremonias y redes de sociabilidad que aseguraban la supervivencia de un pequeño grupo a través de la reproducción de valores, como la solidaridad, la caridad y el apoyo mutuo entre sus integrantes. ${ }^{1} \mathrm{~A}$ este mecanismo pertenecían, como formas de asociación corporativa, las cofradías, las congregaciones, las devociones o hermandades y las mayordomías. Cabe señalar que durante los siglos XVI y XVII estos términos eran empleados por las autoridades virreinales - civiles y religiosas- como sinónimos, por la razón de que todas tenían la finalidad en común de propagar y extender el catolicismo en todos los sectores de la población. Aunque jurídicamente cada una cumplía con diferentes requisitos para su fundación que las hacían diferentes entre sí. Por ejemplo, las cofradías debían contar con la aprobación del obispo para su fundación y estaban integradas en su mayoría por laicos; de la misma manera, las congregaciones también debían contar con el permiso de la autoridad apostólica; por lo general, las integraban los clérigos y la población española acaudalada. Las hermandades, a diferencia de las dos primeras instituciones, no necesitaban de la licencia del ordinario; bastaba simplemente con que el cura local otorgara el permiso para su establecimiento. Finalmente, las mayordomías se desarrollaron en las comunidades rurales, en algunas ocasiones recaían en una sola persona; se encontraban inmersas en la dinámica de la organización políticoreligiosa de los pueblos y barrios; tenían la finalidad de llevar a cabo la festividad del santo patrón al que estaban dedicadas.

En el ámbito social cada forma corporativa cumplía con un rol específico dentro de la comunidad donde se encontraban establecidas. Fue hasta el siglo XVIII, con el cambio coyuntural de la dinastía de los Borbones (que se caracterizó por sus políticas absolutistas), cuando las cofradías tuvieron

${ }^{1}$ Lara Mancuso, Cofradías mineras: religiosidad popular en México y el Brasil. Siglo XVIII (México: El Colegio de México, 2007), 11. 
mayor control por parte de las autoridades novohispanas, en cuanto a su establecimiento y administración.

El objeto de estudio de la presente investigación es la cofradía dedicada a la virgen de Guadalupe, fundada por los indios en el siglo XVII en el santuario del Tepeyac. Se plantea, como problemática central, descubrir la función que tuvo esta agrupación como un instrumento que facilitó la transmisión del culto cristiano y la particular devoción a la guadalupana, desde la segunda mitad del siglo XVII hasta los primeros años del siglo XIX, considerando para su análisis distintas dimensiones: en lo político, lo económico y lo social. Además de esta asociación, los naturales de la jurisdicción eclesiástica del pueblo de Guadalupe fundaron otras dos corporaciones: la del Santo Entierro de Cristo y la de Jesús de las Caídas. Sin embargo, no se localizaron los documentos de sus constituciones y son pocas las fuentes que dan prueba de su existencia. La problemática consiste en identificar cómo coexistieron las tres entidades corporativas establecidas por los indios en el Santuario Guadalupano, desde su fundación en el siglo Xvir hasta la segunda mitad del XVIII, cuando tenían a las mismas autoridades y atendían a la misma feligresía, ya que las autoridades virreinales las suponían en su carácter administrativo como cofradías. Pero fue en el tiempo de las reformas de los arzobispos absolutistas, cuando la mayoría de estas instituciones corporativistas que habían dejado de tener utilidad económica fueron agrupadas en otras, con la finalidad de reducir el número excesivo de cofradías que existía en el territorio novohispano, además de concentrar y controlar los fondos que se podían utilizar para el bienestar de las parroquias. ${ }^{2}$

El escenario donde se localizó, fundó y ejerció sus funciones la cofradía guadalupana fue el territorio eclesiástico del pueblo y santuario de Nuestra Señora de Guadalupe - con sus pueblos sujetos a la parcialidad: Santiago Atzacualco o Zacualco, San Pedro Zacatengo, Santa Isabel Tola y San Juan Ixhuatepec, y los barrios de San Lorenzo y Tlatelolco de las Salinas- al norte de la ciudad de México. Después de analizar la escasa documentación en el Archivo Histórico de la Basílica de Guadalupe, se pudo encontrar la periodización para el estudio de la Cofradía de Nuestra Señora de Guadalupe, que va de 1678 a 1800 distinguiendo dos etapas: la primera se desarrolló de 1678 a 1759, y comprende la fundación y el fortalecimiento de la

${ }^{2}$ Clara García Ayluardo, Desencuentros con la tradición. Los fieles y la desaparición de las cofradías de la ciudad de México en el siglo xviII (México: Fondo de Cultura Económica; Consejo Nacional para la Cultura y las Artes, 2015), 223. 
asociación como organismo corporativo; la segunda se consolidó en el siglo XVIII, en los años que van de 1760 a 1800 , periodo que comprende la reactivación de la cofradía hasta su etapa de decadencia, cuando ya no contaba con los recursos suficientes para llevar a cabo sus funciones y los gastos recaían en la figura del mayordomo.

Pese a la gran cantidad de historiografía que se ha producido sobre la historia del culto de la virgen de Guadalupe, son pocas las investigaciones que se han realizado acerca de las cofradías dedicadas a la imagen de la Guadalupana que se fundaron en su Santuario del Tepeyac y que aborden el carácter corporativo que esta devoción tuvo entre los novohispanos. La primera investigadora que describe el funcionamiento particular de estas asociaciones es Delfina López Sarrelangue, en su libro Una villa mexicana en el siglo XVIII: Nuestra Señora de Guadalupe, ${ }^{3}$ donde ofrece no sólo los datos precisos para su estudio, sino también las directrices para profundizar en el análisis de cada una de las asociaciones en el aspecto social, político y económico; con base en un documento de la segunda mitad del siglo XVIII, la autora afirma que las tres cofradías establecidas por los indios en el santuario del Tepeyac compartían la misma mesa directiva. De igual manera, Alicia Mayer, en su artículo "Las corporaciones guadalupanas: centros de integración 'universal' del catolicismo y fuentes de honorabilidad y prestigio", ${ }^{4}$ deja la ruta para indagar sobre la relación existente entre el movimiento de la contrarreforma y el guadalupanismo novohispano, además de profundizar en el análisis de las corporaciones guadalupanas como un instrumento para el fortalecimiento de la devoción a la virgen de Guadalupe, la historiadora propone que el estudio de estas asociaciones sirve para descubrir el desarrollo de las prácticas religiosas y las creencias que se impulsaron al interior de la sociedad novohispana. Por su parte, Ana Rita Valero de García Lascuráin, en su libro La Archicofradía Universal de Nuestra Señora de Guadalupe. Pasado y presente, ${ }^{5}$ aborda el papel social que tuvo esta institución en el santuario a lo largo de cuatro siglos de historia; esbo-

${ }^{3}$ Delfina López Sarrelangue, Una villa mexicana en el siglo XvIII: Nuestra Señora de Guadalupe, 2a. ed. (México, Universidad Nacional Autónoma de México, Instituto de Investigaciones Históricas; Miguel Ángel Porrúa, 2005).

${ }^{4}$ Alicia Mayer, “Las corporaciones guadalupanas: centros de integración 'universal' del catolicismo y fuentes de honorabilidad y prestigio", en Formaciones religiosas en la América colonial, coordinación de María Alba Pastor y Alicia Mayer (México: Universidad Nacional Autónoma de México, Facultad de Filosofía y Letras, 2000).

${ }^{5}$ Ana Rita Valero de García Lascuráin, La Archicofradía Universal de Nuestra Señora de Guadalupe. Pasado y presente (México: Insigne y Nacional Basílica de Guadalupe, 2002). 
za como perspectivas de investigación el análisis de las indulgencias, y deja la pista para profundizar en el análisis de las cofradías de naturales, en particular, de la que se fundó en la antigua iglesia de los indios. Cabe apuntar que las tres historiadoras le dan mayor seguimiento en sus estudios a la congregación de españoles que se estableció en 1674 en el mencionado recinto, y esbozan algunos datos para la reconstrucción de la historia de la cofradía de indios. De la misma manera, Gustavo Watson Marrón en su obra El templo que unió a Nueva España. Historia del santuario y Colegiata de Guadalupe extramuros de México en el siglo XVIII, ${ }^{6}$ dedica un apartado de su investigación para analizar dos corporaciones dedicadas a la virgen de Guadalupe en la época novohispana: una congregación de españoles y una cofradía de indios; utiliza fuentes inéditas del Archivo Histórico de la Basílica de Guadalupe que amplían la información obtenida en los estudios precedentes. Watson es el primer historiador que da a conocer de manera clara y precisa la historia de la Cofradía de Nuestra Señora de Guadalupe, fundada por naturales, así como las cláusulas de su constitución, dejando la posibilidad abierta para profundizar en el análisis de esta institución.

El presente artículo es el resultado de una investigación más amplia, ${ }^{7} \mathrm{y}$ tiene el objetivo de ampliar la información de la historia de la cofradía de la virgen de Guadalupe fundada por indios, así como dar a conocer la relación entre las otras dos cofradías establecidas también por naturales y comprender a grandes rasgos (por la escasez de fuentes) sus características como organizaciones corporativistas. El análisis de esta asociación explica el carácter corporativo que adquirió la imagen de la Guadalupana entre la sociedad novohispana. La cofradía de indios dedicada a la virgen María en su advocación de Guadalupe fue una institución corporativa que tuvo la

${ }^{6}$ Gustavo Watson Marrón, El templo que unió a Nueva España. Historia del Santuario y Colegiata de Guadalupe extramuros de México en el siglo XVIII (México: Basílica de Guadalupe; Miguel Ángel Porrúa; Seminario Conciliar de México, 2012).

${ }^{7}$ Véase Juan Javier Ortiz Rodea, "La Cofradía de Nuestra Señora de Guadalupe fundada en el Santuario del Tepeyac: 1678-1800. Una cofradía de indios en el mundo novohispano" (tesis de licenciatura, Universidad Autónoma del Estado de México, 2014). En este trabajo se analizó a la cofradía Guadalupana, desde la lente del corporativismo eclesiástico, las fuentes primarias que se utilizaron para la reconstrucción de la historia de la asociación provienen en su mayoría del Archivo Histórico de la Basílica de Guadalupe y son: en primer lugar, su constitución, algunas actas de cabildo que comprenden el periodo de 1760-1767, tres memorias de lo que recolectaban los mayordomos, dos demandas para la recolección de las limosnas, algunos citatorios y papeles sueltos. Desafortunadamente son pocos los documentos que hacen referencia a la Cofradía de Nuestra Señora de Guadalupe, fundada por los indios del Santuario del Tepeyac durante el siglo XviI. 
finalidad de integrar, organizar y tomar en cuenta a la población autóctona de la jurisdicción del pueblo de Guadalupe, que no sólo los congregó para la realización de los actos litúrgicos, sino que también les dio la posibilidad de ocupar algún cargo en el gobierno civil de la república de indios. El presente trabajo se estructura en cuatro apartados: en el primero se da un breve panorama geográfico, histórico y religioso del pueblo y santuario de Guadalupe; en el segundo se analiza a la congregación de españoles de la virgen de Guadalupe como antecedente inmediato para la fundación de la cofradía de indios; posteriormente, en el tercer apartado se examina a la Cofradía de Nuestra Señora de Guadalupe en sus aspectos legal, administrativo, económico y social, a través de las fuentes de archivo; en la cuarta sección se aborda la relación corporativa que se dio entre las tres cofradías de indios establecidas en el santuario del Tepeyac.

\section{El pueblo de indios del santuario de Guadalupe}

Para poder descubrir la función que tuvo una cofradía como institución eclesiástica se debe tomar en cuenta el contexto histórico y político del lugar donde se estableció. En nuestro estudio de caso el escenario donde se fundó y consolidó la cofradía de indios dedicada a la virgen de Guadalupe fue el territorio eclesiástico del pueblo y el santuario de Guadalupe, ubicado al norte de la ciudad de México. Durante el siglo xvi se comenzó a llamar pueblo de Nuestra Señora de Guadalupe al Tepeyac (aunque aún no lo era, debido a que en ese tiempo todavía no se redactaba un documento oficial por parte del monarca español y de las autoridades virreinales que lo validara), también se le conoció como pueblo del Santuario de Guadalupe o pueblo de la ermita de Guadalupe, sujeto a la parcialidad de Santiago Tlatelolco hasta el siglo XVIII como comunidad indígena; pero también formó parte territorial del corregimiento de la ciudad de México por la población española que vivía en este sitio.

El cerro del Tepeyac se encontraba al norte de la parcialidad de Santiago Tlatelolco a una legua $(4.19 \mathrm{~km})$ de distancia; al este limitaba con la laguna de Texcoco, al oeste con los ríos de Tlanepantla y de los Remedios que se juntaban con el río Unido, llamado posteriormente de Guadalupe; detrás del cerro de 40 metros de altura se desprendía la sierra de Guadalupe que la formaban cuatro cerros, llamados de Santa Isabel Tola, Zacahuitzco, Guerrero y el mencionado Tepeyac, siendo esta última la cumbre más 
representativa de la pequeña cadena montañosa ${ }^{8}$ (véase la figura 1). Este lugar se comunicaba con la ciudad de México por la calzada de piedra llamada de Guadalupe, que llegaba al barrio de Santiago Tlatelolco; era una barrera que impedía la comunicación entre las aguas de la laguna, por un lado, y las de los ríos, por el otro. En los primeros años del siglo XVII fue arreglada con mano de obra indígena, y los trabajos fueron dirigidos por el padre Torquemada. ${ }^{9}$

Al iniciar la evangelización en Nueva España, los misioneros franciscanos establecieron una ermita en Tepeaquilla; ${ }^{10}$ con el paso del tiempo esta iglesia pasó a formar parte del clero secular en el periodo del arzobispo Montúfar, quien nombró un vicario que debería cuidar la ermita y administrar los sacramentos no sólo en Guadalupe sino también en las estancias indígenas de los alrededores. ${ }^{11}$ En el año de 1702, el arzobispo de México, don Juan de Ortega y Montañés, ${ }^{12}$ integró en Guadalupe un nuevo curato, en el cual la vicaría ${ }^{13}$ elevaría su rango a parroquia ${ }^{14}$ teniendo su ubicación en la antigua "iglesia de los indios", ${ }^{15}$ ya que en esas fechas se llevaban a cabo los trabajos de la construcción del nuevo santuario. ${ }^{16}$

${ }^{8}$ López Sarrelangue, Una villa mexicana en el siglo XVIII, 15.

${ }^{9}$ Francisco Miranda Godínez, Dos cultos fundantes: los Remedios y Guadalupe (15211649). Historia documental (México: El Colegio de México, 2001), 244.

${ }^{10}$ Nombre que le otorgaron los españoles al Tepeyac para diferenciarlo del poblado de Tepeaca, ubicado en el actual estado de Puebla, hasta el año de 1563 cuando se le comenzó a llamar Guadalupe. Álbum de la Coronación de la Santísima Virgen de Guadalupe (México: Imprenta El Tiempo de Victoriano Agüeros, 1895), 29.

${ }^{11}$ En un primer momento la Vicaría de Guadalupe formó parte de la Parroquia de Santa Catarina Mártir de México.

${ }^{12}$ Gustavo Watson Marrón, "Los templos del Tepeyac, ayer y hoy”, en Memoria del Congreso Guadalupano. "Mucho quiero, muchísimo deseo que aquí me levanten mi templo" 8, 9 y 10 de octubre de 2001 (México: Publicaciones de la Basílica de Guadalupe; Instituto de Estudios Teológicos e Históricos Guadalupanos, 2002), 38.

${ }^{13}$ De acuerdo con el Diccionario de autoridades, una vicaría era una oficina o tribunal donde el vicario ejercía las funciones para llevar a cabo los oficios litúrgicos. Véase en Real Academia Española, Diccionario de autoridades, Serie Biblioteca Romana Hispánica (Madrid: Gredos, 1990), 2:475.

${ }^{14}$ Siguiendo con el Diccionario de autoridades, una parroquia era el lugar donde se administraban, por derecho y obligación, los sacramentos a los fieles y donde se desarrollaba el culto divino y era regida o administrada por el cura o párroco. Ibidem, 135.

${ }^{15}$ A este lugar se le conoció por tradición como la "parroquia de indios", ya que en ese lugar se guardaban los libros de las partidas de bautismo y matrimonio y objetos de liturgia del curato.

${ }^{16}$ En 1695 inició su construcción. Colocó la primera piedra del edificio arquitectónico el arzobispo de México, Francisco de Aguiar y Seijas. El proceso de construcción concluyó 


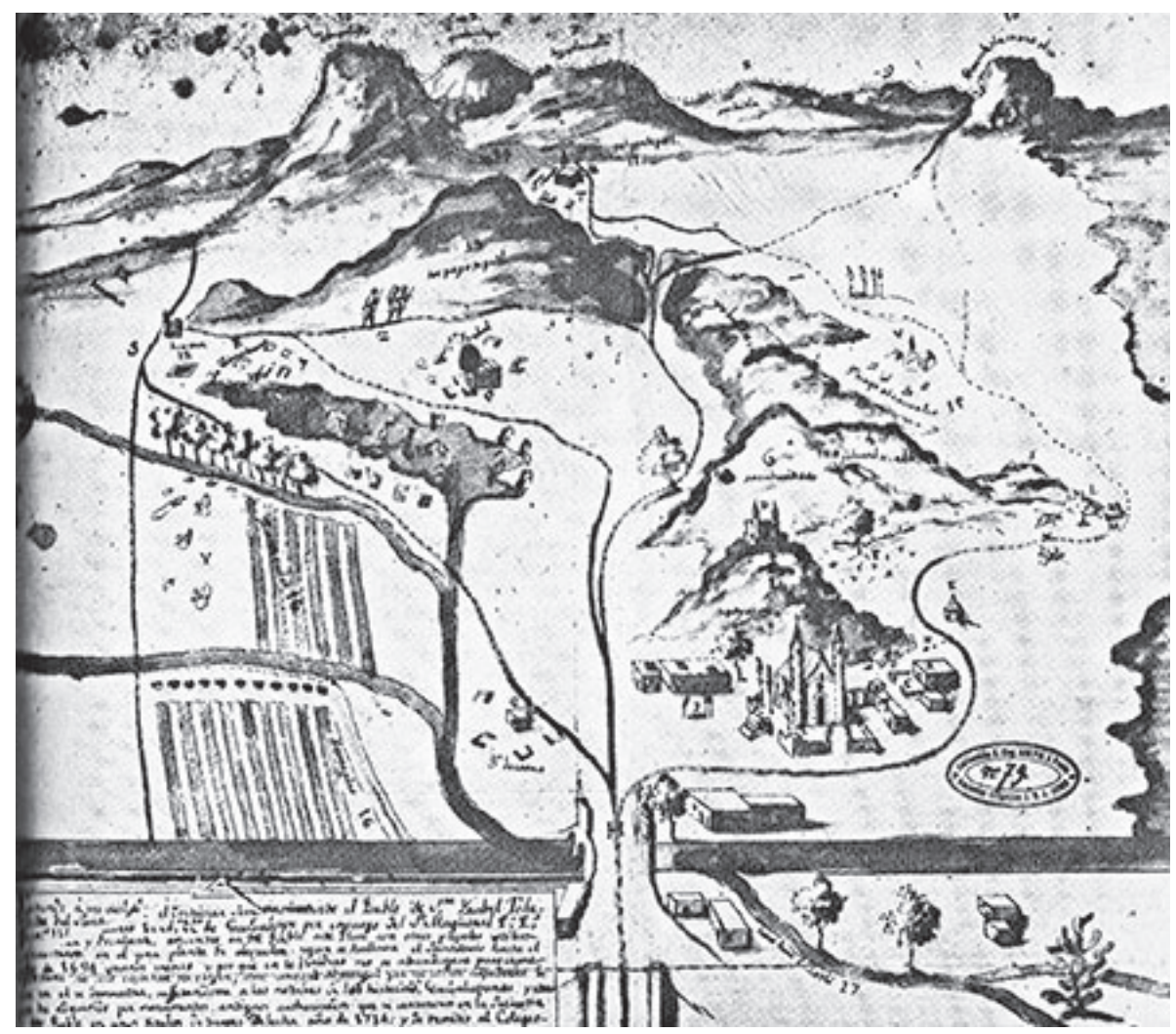

Figura 1. Relevamiento topográfico del Santuario de Nuestra Señora de Guadalupe del Tepeyac y de sus accesos antes de 1694. Plano que contiene la ubicación geográfica del pueblo y santuario de Guadalupe en el siglo XviI, y de los pueblos cercanos que pertenecían a su jurisdicción eclesiástica; Santa Isabel Tola, San Pedro Zacatengo, Santiago Atzacoalco y San Juan Ixhuantepec. En la figura se puede apreciar la topografía del lugar; al fondo, la sierra de Guadalupe, de la cual se desprendía una pequeña cadena montañosa donde sobresale el cerro del Tepeyac, y frente a éste, el santuario dedicado a la virgen de Guadalupe. Fuente: Mapa tomado de Jacques Lafaye, Quetzalcóatl y Guadalupe. La formación de la conciencia nacional en México, 1a. reimp., trad. de Ida Vitale y Fulgencio López Vidarte (México: Fondo de Cultura Económica, 1991, s/p)

hasta 1709 con una solemne celebración encabezada por el duque de Albuquerque, virrey de la Nueva España. Iván Martínez Huerta, "Los estrenos de una casa. Los traslados y fiestas en Guadalupe." Boletín Guadalupano. Información del Tepeyac para los Pueblos de México (Publicación mensual gratuita de la Basílica de Guadalupe, México), n. 105, año Ix (septiembre 2009), 23. 
En 1703 fue designado como primer párroco el bachiller Francisco de Fuentes y Carrión; ${ }^{17}$ el curato estuvo integrado por los pueblos sujetos a la reducción de Guadalupe: Santa Isabel Tola, San Juan Ixhuantepec (Ixhuatepec), Santiago Atzacualco (Atzacoalco) y San Pedro Zacatengo (Zacatenco); además la parroquia contaba con dos barrios: el de San Lorenzo y el de Tlatelolco de las Salinas. ${ }^{18}$ La parroquia o curato de Guadalupe funcionó como órgano eclesiástico hasta 1749 cuando el arzobispo de México, don Manuel Rubio y Salinas, la extinguió perpetuamente y en su lugar erigió la "Insigne y Real Colegiata de Nuestra Señora de Guadalupe", con cabildo, coro, misa capitular, arca, bolsa, sello, archivo, entre otras prerrogativas y una abadía a favor de un presbítero secular, el primer abad de la Colegiata en asumir el cargo, en 1751, fue el doctor don Juan Antonio de Alarcón y Ocaña. El curato no se disolvió del todo, fue agregado al cabildo de la Colegiata y el canónigo magistral ${ }^{19}$ era el sacerdote encargado de atender simultáneamente a la antigua parroquia; en particular administrar los sacramentos, realizar los oficios litúrgicos y vigilar el cumplimiento de las funciones de las cofradías integradas por naturales en la iglesia de los indios.

La mayoría de la población tanto en los pueblos como en los barrios era de indios, pero también había españoles y algunos mestizos que habían establecido sus casas alrededor de la primera ermita dedicada a la virgen de Guadalupe. En los siglos XVI y XviI la reducción de Guadalupe se gobernaba por un alcalde que se elegía anualmente por el común de los pueblos, alternando el puesto con los vecinos de los dos barrios; de igual forma se designaban dos regidores: uno mayor, otro menor y un alguacil. En las comunidades sujetas se elegían del mismo modo a sus respectivas autoridades, alcaldes y regidores. ${ }^{20}$

17 Jesús García Gutiérrez, Efemérides guadalupanas publicadas con motivo de la celebración del IV Centenario de las apariciones de la Santísima Virgen de Guadalupe (México: Antigua Imprenta de Murguía, 1931), 143.

${ }^{18}$ A este último barrio se le conoció primero con el nombre de Tlatelolco de las Salinas (Tlatilulco de acuerdo con la transcripción de los documentos) posteriormente fue llamado barrio de San Bartolomé de las Salinas o simplemente barrio de las Salinas. López Sarrelangue, Una villa mexicana en el siglo XVIII, 20.

${ }^{19}$ Gustavo Watson Marrón, "Significado del nombre 'Insigne y Nacional Basílica de Guadalupe' (2da. parte)”, Boletín Guadalupano. Información del Tepeyac para los Pueblos de México (Publicación mensual gratuita de la Basílica de Guadalupe, México), n. 124, año XI (julio 2011), 34. López Sarrelangue, Una villa mexicana en el siglo XVIII, 84-87.

${ }^{20}$ López Sarrelangue, Una villa mexicana en el siglo XVIII, 23. 
Fue hasta el siglo XviII cuando se erigió formalmente el pueblo de Guadalupe para los indios (1741) y villa para la población española y mestiza (1751). Sin embargo, en 1735 los naturales del pueblo del Santuario de Guadalupe celebraron por primera vez cabildo independientemente de la parcialidad de Santiago Tlatelolco; eligieron a su gobernador, dos alcaldes, dos regidores, un alguacil mayor y un escribano. ${ }^{21}$ Los cuatro pueblos y los dos barrios antes mencionados quedaron como subalternos, y reconocieron a la jurisdicción de Guadalupe como su cabecera. ${ }^{22}$

\section{LA CONGREGACIÓN DE ESPAÑOLES DE LA ViRgEN DE GUADALUPE FUNDADA EN 1674}

Los españoles fueron los primeros en integrar una congregación dedicada a la virgen de Guadalupe en su santuario del Tepeyac; ${ }^{23}$ el 28 de abril de 1674 eligieron como su primer prefecto a don Isidro Sariñana, y en 1675

${ }^{21} \mathrm{El} 22$ de agosto de 1774 se eligieron como oficiales de la república de indios del pueblo del Santuario de Nuestra Señora de Guadalupe a los siguientes naturales principales: el cargo de gobernador fue ocupado por don Francisco de Sales; como alcaldes estuvieron don Fernando José y don Francisco de Escalona; los regidores fueron don Gregorio José de Ferrer y don Salvador de la Cruz. El cargo de alguacil mayor fue desempeñado por don Julián Faustino y como escribano de la república estuvo don José Lucas Hernández. Archivo General de la Nación (en los sucesivo AGN), Indiferente Virreinal, General de Parte, caja 2571, exp. 024, año 1774 , f. 3.

${ }^{22}$ López Sarrelangue, Una villa mexicana en el siglo XVIII, 46-47.

${ }^{23}$ Era una asamblea o grupo de personas que se juntaban y formaban un cuerpo o colectividad para practicar alguna obra piadosa o de devoción. Para que la fundación de una congregación en la Nueva España estuviera dentro del marco de la legalidad era necesario que ésta contara con la autorización apostólica del Sumo Pontífice, o en su defecto tener la aprobación de algún obispo. El gobierno de estas instituciones recaía en la figura del prefecto, que la mayoría de las veces era clérigo secular o regular, dependiendo de la congregación. Los sacerdotes que pertenecían a estas corporaciones las utilizaron como medio para escalar posiciones dentro de la jerarquía eclesiástica y algunos llegaron a ser obispos o representativos prelados (canónigos o prebendados) que ocuparían cargos relevantes dentro de los cabildos eclesiásticos de las catedrales de las principales ciudades novohispanas. Para profundizar sobre este tema, véanse Asunción Lavrin, "La Congregación de San Pedro. Una cofradía urbana del México colonial 1604-1730”, Historia Mexicana (El Colegio de México), n. 4, v. xxix (abril-junio 1980), 562-601, y John F. Schwaller, "Los miembros fundadores de la Congregación de San Pedro México, 1557”, Cofradías, capellanías y obras pías en la América colonial, coordinación de María del Pilar Martínez López-Cano et al. (México: Universidad Nacional Autónoma de México, Instituto de Investigaciones Históricas, 1998), 109-117. 
el papa Clemente X confirmó la formación de la institución. ${ }^{24}$ Esta asociación estuvo integrada únicamente por sacerdotes en sus primeros años de existencia; posteriormente abrieron sus puertas para que laicos españoles acaudalados y de prestigio pudieran pertenecer a la corporación. Para ingresar a la congregación guadalupana los socios debían pagar un real al inscribirse y medio real como contribución semanal, ${ }^{25}$ acto inmediato la asociación le otorgaba al congregante la patente o carta de identidad que lo acreditaba como integrante de la colectividad; en algunos casos en este documento se incluía el sumario de las indulgencias a las que el socio tenía derecho siempre y cuando cumpliera con todos los requisitos para obtenerlas. Cuando un integrante de la congregación fallecía, ésta le otorgaba a sus familiares 30 pesos para ayudar con los gastos funerarios siempre que el congregante hubiese pagado sus cuotas puntualmente. ${ }^{26}$ La fiesta de la congregación de la virgen de Guadalupe se celebraba con gran solemnidad el 12 de diciembre en su santuario. Por el progreso de la institución los cofrades debían acudir confesados con el propósito de participar en el sacramento de la comunión; además los sacerdotes congregantes tenían la obligación de ofrecer las misas el día de la festividad por los socios vivos y difuntos; ellos eran los encargados de llevar la custodia con el Santísimo Sacramento durante la procesión. ${ }^{27}$

En 1675 el arzobispo de México, fray Payo Enríquez de Rivera, encargó a las autoridades de la congregación la construcción de 15 torreones o monumentos que representarían los misterios del rosario en la Calzada de Guadalupe $^{28}$ (conocida actualmente como Calzada de los Misterios). De esta manera la congregación formada por españoles acercó a los novohispanos a externar su religiosidad de manera colectiva a través de la realización de los actos públicos, como las procesiones, las peregrinaciones, los rosarios y las misas, que fortalecían la fe católica entre la sociedad; además, en algunas ocasiones los congregantes ayudaron a embellecer arquitectónicamente

${ }^{24}$ García Gutiérrez, Efemérides guadalupanas, 72.

${ }^{25}$ Archivo Histórico de la Basílica de Guadalupe (en lo sucesivo AHBG), Santuario de Guadalupe, Serie Cofradías, caja 356, exp. 9, año ca. 1777, f. 3.

${ }^{26}$ AHBG, Secretaría Capitular, Serie Cofradías, caja 356, exp. 8, año ca. 1780, f. 2.

${ }^{27}$ AHBg, Secretaría Capitular, Serie Cofradías, caja 391, exp. 33, año ca. 1705, f. 1. Véase también Watson Marrón, El templo que unió a Nueva España, 138.

${ }^{28}$ Martha Fernández, La imagen del templo de Jerusalén en la Nueva España (México: Universidad Nacional Autónoma de México, 2003), 144. 
el santuario con sus limosnas y donaciones; también patrocinaron varias obras de arte de manera colectiva.

La congregación era dirigida por un prefecto que en sus primeros años de existencia era un sacerdote secular de acuerdo con su constitución; posteriormente, en 1675 se decidió que el cargo se turnara: un año le correspondía a un clérigo y el siguiente a un laico; ${ }^{29}$ por ejemplo, el 18 de diciembre de 1768 ocupó el cargo como prefecto de la asociación don Joaquín Dongo, laico adinerado de origen español. ${ }^{30}$ En 1755 la institución estaba integrada por 65 socios, de los cuales 36 eran hombres y 29 mujeres; ${ }^{31}$ en la segunda mitad del siglo XVIII, en el año de 1786, la congregación admitió oficialmente a toda la población sin exigencias étnicas ni sociales; ${ }^{32}$ la única condición que se pedía para que los individuos ingresaran a la asociación era que profesaran fielmente la devoción a la virgen de Guadalupe. Durante el siglo xix la congregación fue elevada a la categoría de archicofradía por el papa León XIII, el 9 de septiembre de 1890;33 esta institución agrupó a las cofradías y congregaciones que se establecieron en el santuario del Tepeyac desde el siglo xviI. Fue hasta el 12 de diciembre de 1899 cuando el arzobispo de México, don Próspero María Alarcón y Sánchez de la Barquera, confirmó la erección de la asociación y nombró como su primer director general al abad Leopoldo Ruiz. ${ }^{34}$ En la actualidad esta institución persiste con el nombre de Archicofradía Universal de Santa María de Guadalupe en la Insigne y Nacional Basílica de Guadalupe, presidida por la doctora Ana Rita Valero de García Lascuráin.

${ }^{29}$ Watson Marrón, El templo que unió a Nueva España, 141.

${ }^{30}$ García Gutiérrez, Efemérides guadalupanas, 228.

${ }^{31}$ AHBg, Secretaría Capitular, Serie Cofradías, caja 356, exp. 25, año ca. 1755, f. 3.

${ }^{32}$ Valero de García Lascuráin, La Archicofradía Universal de Nuestra Señora de Guadalupe, 49.

${ }^{33}$ Era una institución que reunía a dos o más cofradías que tenían ciertas características en común, como la advocación a la que estaban dedicadas o el fin que perseguían; esta asociación corporativa debía ser erigida por el sumo pontífice a perpetuidad, sin que se pudiera trasladar a otra parte, además de que una cofradía no podía ser agregada a más de una archicofradía. Alicia Bazarte Martínez, Las cofradías de españoles en la ciudad de México (15261860) (México: Universidad Autónoma Metropolitana, Azcapotzalco, 1989), 34; véase también Dagmar Bechtloff, Las cofradías en Michoacán durante la época de la Colonia: la religión y su relación política y económica en una sociedad intercultural, traducción de Joaquín Francisco Zaballa Omaña (México: El Colegio de Michoacán; El Colegio Mexiquense, 1996), 65.

${ }^{34}$ Xavier Escalada, Enciclopedia Guadalupana. Temática, histórica y onomástica (México: Dos Colinas Vaticano y Tepeyac, 1995), 1:66. 


\section{La Cofradía de Nuestra Señora de Guadalupe FUNDADA POR INDIOS EN 1678}

Las corporaciones guadalupanas (la congregación de españoles y la cofradía de indios $)^{35}$ fundadas en el santuario del Tepeyac en la segunda mitad del siglo XVII, como instituciones corporativas, promovieron el culto a la virgen de Guadalupe, en primer lugar a nivel local o regional para que posteriormente, en el siglo xviII, esta devoción se convirtiera en una de las más representativas del virreinato de la Nueva España. ${ }^{36}$ En la época novohispana una cofradía era una asociación de fieles laicos llamados cofrades, reunidos en torno al culto religioso (a algún misterio de la vida de Cristo, advocación de la Virgen o bajo el patronato de algún santo), con la finalidad de promoverlo y acrecentarlo mediante el ejercicio de obras caritativas y de asistencia espiritual, así como para fomentar la solidaridad, la seguridad, la fraternidad y la identidad entre los socios al interior de la corporación. Las cofradías de indios fueron instituciones nucleares de la vida local indígena, revestidas de símbolos cívico-religiosos, gracias a su capacidad de desarrollar determinadas funciones políticas, sociales y económicas para consolidar las identidades colectivas. ${ }^{37}$

\section{Aspecto legal de la cofradía}

La legislación eclesiástica y civil del periodo novohispano apuntaba que para poder instituir una cofradía, dentro del marco de la legalidad, se debía contar con la autorización del obispo de la diócesis donde se establecía y de un representante real que avalara la fundación de la institución, según las normas impuestas por la Corona y la Iglesia. La historia de la cofradía

${ }^{35}$ De acuerdo con María Alba Pastor, una corporación dedicada a un solo culto público en particular podía estar dividida en grupos étnicos como en nuestro caso, donde había una congregación para españoles y una cofradía para indios, ambas instituciones dedicadas a la virgen María en su advocación de Guadalupe. María Alba Pastor, "La organización corporativa de la sociedad novohispana”, en Formaciones religiosas en la América colonial, coordinación de María Alba Pastor y Alicia Mayer (México: Universidad Nacional Autónoma de México, Facultad de Filosofía y Letras, 2000), 104.

${ }^{36}$ Alicia Mayer, "Las corporaciones guadalupanas", 183.

${ }^{37}$ Eloy Gómez Pabellón, "El sistema de cargos en Mesoamérica: de fundación piadosa a institución político-religiosa”, Revista Española de Antropología Americana (Ediciones Complutense), v. 46 (2016), 65. 
de Nuestra Señora de Guadalupe fundada por naturales inició el 16 de noviembre de 1678, cuando el fiscal de doctrina, don Juan Antonio, y los indios principales de los pueblos pertenecientes a la jurisdicción de Guadalupe ${ }^{38}$ acudieron a ver al abogado de los Reales Consejos don Lope Cornejo de Contreras, ${ }^{39}$ para pedir licencia para fundar una cofradía a semejanza de la congregación establecida por los españoles en 1674: "En el año de 1678 dicen los indios de los quatro pueblos que en una Hermita y casa de Novenas que esta inmediata a la Hermita y Iglesia principal han colocado a un costado una efigie y retrato de la original por la constante tradición de que allí fue la primera Aparición de la Señora y piden licencia para fundar allí una cofradía donde no se pueda mudar a otra parte". ${ }^{40}$

La petición fue informada al vicario capellán de la ermita y santuario de Guadalupe, el bachiller Alonso de Hita, ${ }^{41}$ días después de la primera solicitud. El 23 de noviembre del mismo año se dio la respuesta a favor de la cofradía de los naturales de sus pueblos y doctrinas; el sacerdote dijo que convenía fundar la institución y concedió la licencia para que se pudieran juntar a hacer, formar y otorgar las reglas y constituciones para el buen funcionamiento de la corporación. ${ }^{42}$ Después los interesados se reunieron para realizar las reglas y constituciones que regirían a la institución de acuerdo con el derecho canónico vigente, ${ }^{43}$ con la legislación eclesiástica

${ }^{38}$ Los fundadores de la corporación fueron los naturales principales de la parcialidad, quienes gozaban de prestigio social, económico y político al interior de la comunidad; las cofradías rurales permitieron que la nobleza indígena tuviera participación dentro de la organización corporativa de la sociedad. Los indios principales eran: don Francisco Joseph, don Diego Gerónimo, don Martín Francisco, don Juan Felipe, don Nicolás Lorenzo, don Juan Nicolás, Juan Felipe, don Juan Luis, don Juan de Santiago, don Diego Juan, don Nicolás de San Diego, don Luis Bartolomé de Francia, don Juan Diego, don Salvador Andrés, Bartolomé de la Cruz, Juan Bentura, don Miguel Fernández, don Lucas Juan, don Miguel Juan, don Bartolomé García, don Juan Thomas, Melchor Francisco, Joseph Valeriano, don Juan Antonio, don Francisco Joseph, Pedro López. AнBg, Santuario de Guadalupe, Serie Cofradías, caja 378, exp. 12, año ca. 1740 , f. 1.

${ }^{39}$ AHBg, Secretaría Capitular, Serie Cofradías, caja. 357, exp. 5, año 1760-1762, f. 6.

${ }^{40}$ AHBG, Santuario de Guadalupe, Serie Cofradías, caja 378, exp. 12, año ca. 1740, f. 1.

${ }^{41}$ Watson Marrón, El templo que unió a Nueva España, 143.

${ }^{42}$ AHBG, Santuario de Guadalupe, Serie Cofradías, caja. 357, exp. 5, año 1760-1762, f. 9.

${ }^{43}$ De acuerdo con los cánones eclesiásticos, las cofradías debían tener un nombre tomado de los atributos de Dios, de los misterios de la religión cristiana, de las fiestas de Cristo y de la virgen María, o de los santos patronos; además, debían fundarse en un templo, capilla u oratorio en concreto; este sería el lugar donde los socios se reunirían periódicamente para acrecentar el culto divino a través de la realización de las actividades litúrgicas, como procesiones, misas, rezos, así como lo referente a la organización de la festividad del santo 
(Primer Concilio Provincial Mexicano) ${ }^{44}$ y con las normas civiles (Leyes de Indias). ${ }^{45}$ Una vez redactados los estatutos, fueron llevados para que el juez provisor de los naturales, don Lope Cornejo de Contreras, ${ }^{46}$ los revisara y confirmara el 27 de febrero de 1679 en nombre del arzobispo de México y virrey de la Nueva España, don fray Payo Enríquez de Rivera (de la orden de San Agustín); a partir de ese momento la institución comenzó a desempeñar sus funciones dentro del marco de la legalidad como organismo corporativo.

De acuerdo con la documentación sobre la cofradía guadalupana fundada por indios, se distinguen dos grandes periodos de tiempo para el análisis de la asociación: el primero va de 1678 al año de 1759 cuando se fundó y consolidó la corporación. Al finalizar el siglo xviı el arzobispo de México Francisco de Aguiar y Seijas inició con un programa que pretendía reorganizar, regularizar y consolidar a las cofradías en su territorio eclesiástico, con la finalidad de mejorar su administración, después de varias visitas pastorales el prelado encontró que estas corporaciones presentaban irregularidades en cuanto al manejo de sus cuentas y que no se respetaban sus

patrón de la asociación como una de sus principales tareas institucionales. Gonzalo Arteche B., El Código de Derecho Canónico. Traducido y comentado (Santiago de Chile: Imprenta San Francisco, 1944), 1:500.

${ }^{44} \mathrm{El}$ decreto LXXv ordenaba que no se establecerían cofradías sin licencia del obispo o de alguna autoridad eclesiástica; además se obligaba a las dignidades clericales a examinar, aprobar y confirmar las constituciones y estatutos; si esta disposición se pasaba por alto se anulaban los reglamentos y los cofrades deberían pagar diez pesos como multa. Leticia Pérez Puente et al., "Primer y segundo concilios", en Concilios provinciales mexicanos. Época colonial, coordinación de María del Pilar Martínez López-Cano, versión en CD-ROM (México: Universidad Nacional Autónoma de México, Instituto de investigaciones Históricas, 2004), 85.

${ }^{45}$ La legislación indiana reglamentó a las cofradías con la ley 25 , título 4 , libro 1 ; ésta decía que las cofradías debían establecerse bajo tres requisitos esenciales dentro de la normatividad civil: a) debían contar con la licencia del monarca o de alguna autoridad representante del rey para su institución; b) la revisión y aprobación de sus estatutos por el Consejo de Indias además de la autorización del obispo local; y c) los cofrades sólo podían reunirse siempre y cuando estuviese presente un delegado real y el cura local. Juan Manzano Manzano, Recopilación de leyes de los Reynos de Indias, prólogo de Ramón Méndez y Pidal (Madrid: Ediciones Cultura Hispánica, 1973), 1:20. En ciertas ocasiones dichos requerimientos se pasaban por alto; por tal motivo se promulgó la ley 6 , título 2, libro 1, que prohibía, por orden real, fundar o erigir cofradías, congregaciones o hermandades sin la aprobación civil y eclesiástica para su funcionamiento, por lo que si no contaban con estos requisitos quedaban extintas y carecían de carácter legal. Justo Donoso, Instituciones de derecho canónico americano (París: Librería de la Rosa y Bouret, 1852), III:114.

${ }^{46}$ García Gutiérrez, Efemérides guadalupanas, 38. 
constituciones. ${ }^{47}$ La segunda etapa de la cofradía guadalupana de indios inicia el 18 de junio de 1760, cuando los oficiales de la cofradía y los demás indios de la jurisdicción del pueblo de Guadalupe solicitaron la reactivación de la asociación al juez provisor de los naturales del arzobispado de México don Francisco Jiménez Caro, quien tendría la función de supervisar que la asociación llevara a cabo sus actividades de acuerdo con sus constituciones y finaliza en el año de 1800 cuando la institución comienza a entrar en decadencia al no contar con bienes, ni rentas, ni recursos económicos para llevar a cabo sus funciones y los gastos recaían en la persona del mayordomo.

El documento que arroja la mayor información para la reconstrucción de la historia de la Cofradía de Nuestra Señora de Guadalupe es su constitución, donde se describen las reglas o cláusulas que los cofrades tenían que cumplir al pie de la letra para el buen funcionamiento de la institución, en los ámbitos administrativo, económico y social. ${ }^{48}$ La primera regla de su constitución apuntaba que la cofradía quedaba establecida perpetuamente en la iglesia y ermita que estaba inmediata a la iglesia principal (la antigua iglesia de los indios) ${ }^{49}$ con la condición de que no se trasladara a otro templo, ermita, capilla o altar bajo ningún pretexto, con el título o nombre de Nuestra Señora de Guadalupe, ${ }^{50}$ en recuerdo de su milagrosa aparición en la tilma del indio Juan Diego; además, la segunda cláusula estipulada en el mismo documento indicaba que todos los cofrades estaban obligados tanto a cuidar como asistir a la cofradía y que la ermita y casa de novenas ${ }^{51}$ se

${ }^{47}$ Carolina Yveth Aguilar García, "La reforma arzobispal y monárquica de cofradías y otras asociaciones seglares en ciudad de México y pueblos circunvecinos, 1750-1808” (tesis doctoral, México, Universidad Nacional Autónoma de México, 2019), 176-177.

${ }^{48}$ En el manuscrito se exponen dos de los principales propósitos de la corporación; por un lado, integrar a los indios que vivían en los pueblos cercanos al Tepeyac a la fe católica y, por el otro, propagar la devoción a la virgen de Guadalupe entre la población novohispana.

${ }^{49}$ Este templo fue construido de 1647 a 1649 por el bachiller Luis Lasso de la Vega (capellán de Guadalupe de 1647 a 1657) con mano de obra indígena. Esta pequeña iglesia tenía un altar y un retablo dorado; junto a éste se construyó una casa u hospedería para que la ocuparan los indios del partido de Guadalupe y del Arzobispado de México que acudían en procesión al Santuario del Tepeyac. Luis T. Montes de Oca, Las tres primeras ermitas guadalupanas del Tepeyac: algunas conjeturas acerca de las ruinas arqueológicas del siglo XVI, encontradas en la sacristía de la parroquia archipresbitral de Santa María de Guadalupe (México: Imprenta Labor Mix, 1937), 106.

${ }^{50}$ AHBG, Secretaría Capitular, Cofradías, caja 357, exp. 5, año 1760-1762, f. 13.

${ }^{51}$ Hospedería que servía para que algunos fieles pudieran retirarse por algunos días a hacer ejercicios espirituales o rezar novenas. Fue construida por órdenes del arzobispo de México Francisco de Manso y Zúñiga en 1632 y duró hasta 1751, tiempo en el que se derrumbó para aumentar la sacristía de la Iglesia Colegiata. Watson Marrón, "La Parroquia 
tuviera siempre aseada y con la decencia debida, si le ocurría algún deterioro causado por el tiempo debía ser reparado con las limosnas de la asociación. ${ }^{52}$

Aspecto administrativo de la cofradía

Toda cofradía debía contar con una mesa directiva encargada de dirigir a la asociación, con la finalidad de vigilar que sus funciones y constituciones se cumplieran cabalmente. La tercera regla de la constitución de nuestra cofradía relata que, a finales del siglo Xviı y principios del xviII, el día 12 de diciembre de cada año a las cuatro de la tarde se tenían que juntar en la ermita todos los miembros de la asociación en presencia del padre vicario de la doctrina y partido de Guadalupe, para elegir a los integrantes de la mesa directiva de la institución..$^{53}$

Los oficiales que representaban a la asociación eran: un rector, un mayordomo y seis diputados ${ }^{54}$ que eran representados por un individuo de cada uno de los cuatro pueblos y de los dos barrios sujetos a la jurisdicción eclesiástica (véase el cuadro 1). Por lo que las principales funciones de la mesa consistían por un lado en asesorar y por el otro en discutir los asuntos de la asociación y ejecutar las decisiones colectivas aprobadas por la elección de la mayoría de los integrantes. ${ }^{55}$ Los representantes de la cofradía eran elegidos mediante una votación secreta, por espacio de un año con opción a ser reelegidos, si así era lo más conveniente para la institución, siempre y cuando su conducta fuera adecuada.

Para ocupar los cargos más relevantes dentro de la institución (que eran el del rector y el del mayordomo) se proponía a individuos que profesaban amor y devoción a la cofradía, además de que éstos debían ser caritativos y se comprometían a velar por aumentar los bienes y limosnas de la institución; de igual manera debían tener buena posición económica, además

Antigua de Indios”, Boletín Guadalupano. Información del Tepeyac para los Pueblos de México (Publicación mensual gratuita de la Basílica de Guadalupe, México), año Xı, n. 126 (septiembre 2011), 34 .

${ }^{52}$ AHBg, Secretaría Capitular, Cofradías, caja 357, exp. 5, año 1760-1762, f. 14.

${ }^{53}$ AHBg, Secretaría Capitular, Cofradías, caja 357, exp. 5, año 1760-1762, f. 15.

${ }^{54}$ AHвG, Secretaría Capitular, Cofradías caja 357, exp. 3, año ca. 1755, f. 2.

55 García Ayluardo, Desencuentros con la tradición, 114. 


\section{Cuadro 1}

Mesa directiva de la Cofradía de Nuestra Señora de Guadalupe ELEGIDA EL 18 DE JUNIO DE 1760

\begin{tabular}{ll}
\hline \multicolumn{1}{c}{ Cargo en la cofradía } & \multicolumn{1}{c}{ Nombre del oficial } \\
\hline Rector & Don Felipe de la Trinidad \\
Mayordomo interino & Don Juan Gregorio y Aquino \\
Diputado del barrio de San Lorenzo & Don Marcos Alejandro \\
Diputado del barrio de Tlatilulco de las Salinas & Don Juan Matías \\
Diputado del pueblo de Santiago Atzacualco & Don Tomás Fernando \\
$\begin{array}{l}\text { Diputado del pueblo de San Juan Ixhuatepec } \\
\text { Diputado del pueblo de San Pedro Zacatengo }\end{array}$ & Don Francisco Antonio \\
Diputado del pueblo de Santa Isabel Tola & Don Pedro Antonio \\
\hline
\end{tabular}

Fuente: AHBg, Secretaría Capitular, Serie Cofradías, caja 357, exp. 5, año 1760-1762, f. 35 .

de gozar de honorabilidad y prestigio al interior de la comunidad indígena ${ }^{56}$ (véase el cuadro 2). Durante la segunda mitad del siglo XVIII los integrantes de la cofradía se reunían a la mitad del año (a partir del mes de junio, julio o agosto) para elegir a los candidatos que ocuparían los principales cargos de la institución. Una carta citatorio que enviaba el juez eclesiástico del Provisorato de Indios y Chinos del Arzobispado de México al canónigo magistral de la colegiata servía para convocar a los indios de los pueblos y barrios que formaban parte de la asociación; casi por lo regular la asamblea se realizaba a las ocho de la mañana después de que los cofrades habían asistido a misa; era obligación de la autoridad clerical supervisar que este acto se llevara a cabo sin contratiempos. ${ }^{57}$

Es preciso señalar que en algunas ocasiones los oficiales de la cofradía llegaron a formar parte del cabildo de la república de indios del pueblo de Guadalupe; de este modo la asociación religiosa sirvió como instrumento para alcanzar y desempeñar un cargo dentro de la comunidad civil, por lo

${ }^{56}$ Estas eran las cualidades que debía tener el individuo que deseaba alcanzar un puesto dentro de la mesa directiva de la cofradía y que se sitúan dentro de las características del corporativismo novohispano.

${ }^{57}$ AHBG, Secretaría Capitular, Serie Cofradías, caja 340, exp. 71, año 1678, f. 1. AнвG, Secretaría Capitular, Serie Cofradías, caja 346, exp. 9, año 1772, f. 1. AHBG, Secretaría Capitular, Serie Cofradías, caja 346, exp. 30, año 1778, f. 1. 
Cuadro 2

RECTORES Y MAYORDOMOS QUE TUVO LA COFRADÍA DE Nuestra SeÑora de Guadalupe de 1760-1767

\begin{tabular}{cll}
\hline Año & \multicolumn{1}{c}{ Nombre del rector } & \multicolumn{1}{c}{ Nombre del mayordomo } \\
\hline 1760 & Don Felipe de la Trinidad & Don Juan Gregorio y Aquino \\
1761 & Don Andrés de la Trinidad & Don Félix de la Trinidad \\
1762 & Don José de Escalona & Don Hipólito Casiano \\
1763 & Don Eugenio Antonio & Don Manuel George \\
1764 & Don Francisco de Sales & Don Santiago José \\
1765 & Don José Joaquín Morales & Don Matías de Escalona \\
1766 & Don Juan de Rosas & Don Hipólito Casiano \\
1767 & Don Francisco José de Escalona & Don Manuel George \\
\hline
\end{tabular}

Fuente: AHBg, Secretaría Capitular, Serie Cofradías, caja 357, exp. 5, año 1760-1762, f. $35-55$.

que ambas instituciones, tanto la cofradía como el cabildo, desarrollaron un sistema de elección y rotación de cargos al interior de la colectividad durante el siglo XVIII. ${ }^{58}$ Por ejemplo, en 1739 don Juan de los Ángeles fue electo mayordomo de la cofradía; dos años después, en 1741 y 1742, ocupó el cargo de gobernador del pueblo de Guadalupe, ${ }^{59}$ y en 1774 fue designado para ocupar el puesto de alcalde ordinario de la parcialidad de San Juan Ixhuatepec. ${ }^{60}$ Otro personaje que desempeñó puestos de elección popular tanto en la cofradía como en la república de indios de Guadalupe fue don Juan Claudio, quien en 1740 fue electo mayordomo de la asociación, un año antes de que se desempeñara como alcalde ordinario de la misma parcialidad. ${ }^{61}$ De esta forma se puede apreciar que no cualquier cofrade podía desempeñar cargos de representatividad religiosa y civil; solamente aquellos individuos que por su posición social de noble y su poder económico dotaban de prestigio a cada corporación, se percibe la existencia de una jerarquía social que permitía al socio ascender en la escala tan compleja del corporativismo novohispano. ${ }^{62}$

\footnotetext{
${ }^{58}$ Pastor, "La organización corporativa de la sociedad novohispana”, 120.

${ }^{59}$ López Sarrelangue, Una villa mexicana en el siglo XVIII, 137.

${ }^{60}$ AGN, Indiferente Virreinal, General de Parte, caja 2571, exp. 024, año 1774, f. 3.

${ }^{61}$ AHBg, Santuario de Guadalupe, Serie Cofradías, caja 269, exp. 52, año ca. 1741, f. 1.

${ }^{62}$ Gómez Pabellón, "El sistema de cargos en Mesoamérica", 56.
} 
Aspecto económico de la cofradía

Los recursos económicos de la asociación provenían de las cuotas que daban los socios, ${ }^{63} \mathrm{y}$ de las limosnas que se recogían por todos los pueblos del Arzobispado de México para que se ayudaran a pagar sus gastos. De acuerdo con la octava cláusula de la constitución de la Cofradía de Nuestra Señora de Guadalupe se establecía que cada año se podía pedir y recolectar públicamente las limosnas por todos los pueblos sujetos a la jurisdicción de Guadalupe, así como de los de la ciudad de México, mediante una o dos demandas aprobadas por el juez provisor de los naturales del Arzobispado de México. ${ }^{64}$ Por esa razón, el 22 de noviembre de 1679 los oficiales de la institución acudieron ante la autoridad competente para que se les otorgara la licencia para demandar la limosna con la condición de que el vicario de la ermita de Guadalupe, el bachiller Alonso de Hita, observara lo que se pedía y se gastara únicamente para el culto y servicio de la imagen. ${ }^{65} \mathrm{Du}$ rante el siglo XVIII, aproximadamente en el año de 1778, la licencia para recolectar la limosna era otorgada al rector y al mayordomo de la corporación por espacio de un año, con el deber de renovarla ante el Provisorato de Indios, cuando este comprobante prescribiera. ${ }^{66}$

Era común que lo que se recolectaba de las limosnas no alcanzaba para financiar los gastos de la institución, por lo que el mayordomo en turno debía de aportar lo necesario de su propio dinero. En 1799 el mayordomo

${ }^{63}$ En el siglo XVII la cuota para la admisión de los cofrades era de cuatro reales de plata para los hombres y las mujeres dos, además de ayudar con los gastos con la limosna que pudieran. Aнвg, Santuario de Guadalupe, Serie Cofradías, caja 378, exp. 12, año ca. 1740. Como no todos los indios podían cubrir las cuotas económicas durante el siglo XviII, la institución cobraba por igual sin distinción de género dos reales y como contribución mensual un real. Aнвg, Secretaría Capitular, Serie Cofradías, caja 357, exp. 5, año 1760-1762, f. 33.

${ }^{64}$ AHBg, Secretaría Capitular, Serie Cofradías, caja 357, exp. 5, año 1760-1762, f. 20-21.

${ }^{65}$ AGN, Indiferente Virreinal, Serie Cofradías y Archicofradías, caja 2692, exp. 12, año 1679, f. 1.

${ }^{66}$ AGN, Cofradías y Archicofradías, caja 4762, exp. 2, año 1778, f. 1 . El 14 de junio de 1786 el doctor don Manuel Antonio Sandoval, juez provisor del Arzobispado de México, concedió la aprobación para llevar a cabo la colecta de los donativos dentro y fuera de la ciudad de México; a los encargados se les pedía que todo lo que se recogía debía ser apuntado además de que se comprometían a llevar una imagen de la virgen de Guadalupe en un cajón con la mayor decencia; no debían dejarla en casas particulares ni acompañarla de música profana o de mujeres; tenían que evitar a toda costa los excesos. AHBg, Secretaría Capitular, Serie Cofradías, caja 403, exp. 18, año 1786, f. 2. 
don Juan de la O recabó 245 pesos, cinco reales, en las 52 semanas del año; ${ }^{67}$ en 1800 este oficial alegaba que la cofradía tenía pocos cofrades sin rentas ni bienes, y sólo colectaba anualmente para la fiesta del mes de noviembre 180 pesos, de los cuales 74 se gastaban en la misa con sermón, procesión y asistencia de ministros, 50 pesos en fuegos y 82 en cera; lo que faltaba tenía que correr a cargo del mayordomo. ${ }^{68}$ Esta situación que se presentó en la asociación guadalupana a lo largo del siglo xvin confirma que únicamente podían acceder a ocupar el cargo de mayordomo aquellos socios con los suficientes recursos económicos para hacer frente a los gastos que no podía cubrir en su totalidad la cofradía (véase el cuadro 3 ).

\section{Cuadro 3}

COMPARACIÓN ENTRE LA CANTIDAD DE INGRESOS Y EGRESOS DE LA COFRADÍA de Nuestra SeÑora de Guadalupe durante el Siglo XVIII

\begin{tabular}{|c|c|c|c|c|}
\hline Año & Nombre del mayordomo & $\begin{array}{l}\text { Ingresos } \\
\text { (limosnas) }\end{array}$ & Egresos & $\begin{array}{l}\text { Diferencia pagada } \\
\text { por el mayordomo }\end{array}$ \\
\hline 1740 & $\begin{array}{l}\text { Don Nicolás de } \\
\text { Guadalupe }\end{array}$ & 222 pesos & $\begin{array}{l}664 \text { pesos, } \\
\text { cuatro reales }\end{array}$ & $\begin{array}{l}442 \text { pesos, } \\
\text { cuatro reales }\end{array}$ \\
\hline 1745 & Don Juan Claudio & $\begin{array}{l}73 \text { pesos, un } \\
\text { real y medio }\end{array}$ & $\begin{array}{l}556 \text { pesos, un } \\
\text { real y medio }\end{array}$ & $\begin{array}{l}483 \text { pesos, un } \\
\text { real y medio }\end{array}$ \\
\hline 1749 & Don Julián Antonio & $\begin{array}{l}182 \text { pesos, } \\
\text { cinco reales }\end{array}$ & $\begin{array}{l}620 \text { pesos, un } \\
\text { real y medio }\end{array}$ & $\begin{array}{l}438 \text { pesos, tres } \\
\text { reales y medio }\end{array}$ \\
\hline 1751 & Don Matías Escalona & $\begin{array}{l}180 \text { pesos, } \\
\text { cuatro reales }\end{array}$ & $\begin{array}{l}568 \text { pesos, dos } \\
\text { reales }\end{array}$ & $\begin{array}{l}388 \text { pesos, dos } \\
\text { reales }\end{array}$ \\
\hline 1760 & $\begin{array}{l}\text { Don Juan Gregorio } \\
\text { y Aquino }\end{array}$ & $\begin{array}{l}568 \text { pesos, } \\
\text { tres reales }\end{array}$ & $\begin{array}{l}618 \text { pesos, dos } \\
\text { tomines }\end{array}$ & $\begin{array}{l}50 \text { pesos, dos } \\
\text { reales y medio, } \\
6 \text { tomines }\end{array}$ \\
\hline 1800 & Don Juan de la O & 180 pesos & 206 pesos & 26 pesos \\
\hline
\end{tabular}

Fuente: AHBg, Santuario de Guadalupe, Serie Cofradías, caja 269, exp. 52, año ca. 1741, f. 3. Aнвg, Santuario de Guadalupe, Serie Cofradías, caja 269, exp. 78, año. 1745, f. 3. AнBg, Santuario de Guadalupe, Serie Cofradías, caja 270, exp. 59, año 1749, f. 4. AHBg, Clavería, Serie Cofradías, caja 270, exp. 56, año 1751, f. 3. AHвg, Secretaría Capitular, Serie Cofradías, caja 357, exp. 5, año 1760-1762, f. 37. AGN, Instituciones Coloniales, Clero Regular y Secular, caja 24, v. 112, exp. 1, año 1801, f. 21.

f. 7 .

${ }^{67}$ AGN, Instituciones Coloniales, Clero Regular y Secular, caja 24, v. 112, exp. 1, año 1801,

${ }^{68}$ AGN, Instituciones Coloniales, Clero Regular y Secular, caja 24, v. 112, exp. 1, año 1801, f. 21 . 
Para Clara García Ayluardo las cofradías rurales o indígenas, como instituciones económicas y financieras, muchas veces sostuvieron a las parroquias así como a los párrocos, y cubrieron los gastos del culto, como el mantenimiento del templo y los objetos para la liturgia. También las actividades financieras ayudaron a realizar la festividad del santo titular de la asociación. ${ }^{69}$ La Cofradía de Nuestra Señora de Guadalupe, fundada por naturales, no logró acumular grandes cantidades de dinero en comparación con las cofradías de españoles establecidas en la ciudad de México, ni mucho menos adquirió grandes bienes; los recursos económicos que se obtenían dentro de la asociación nada más servían para la realización de las fiestas, los pagos de los derechos parroquiales, las ceras, las flores para la iglesia, y para cubrir los gastos de la reparación de la ermita de los indios y la casa de novenas.

\section{Aspecto social de la cofradía}

Dentro de las actividades que desempeñaba la cofradía en el ámbito social se encontraban la organización y la realización de las fiestas, los oficios divinos, así como, por su carácter caritativo y de beneficencia, visitar a los cofrades enfermos y proporcionar lo necesario para el entierro de un socio. La realización de las festividades religiosas eran los actos sociales más representativos de las cofradías y captaban la atención de toda la población. Los cofrades realizaban sus fiestas con el mayor lucimiento; en la mayoría de los casos se acompañaban de grandes banquetes, danzas y fuegos artificiales, sin dejar de lado la participación en los oficios litúrgicos. La asociación de Nuestra Señora de Guadalupe celebraba tres festividades importantes a lo largo del año litúrgico: la primera de ellas era la de la natividad de la virgen María, ${ }^{70}$ que se llevaba a cabo el 8 de septiembre; la segunda

${ }^{69}$ Clara García Ayluardo, "Para escribir una historia del cristianismo en México; las cofradías novohispanas y sus fuentes”, en De sendas, brechas y atajos. Contexto y crítica a las fuentes eclesiásticas, siglos XVI-XVIII, coordinación de Doris Bieñko de Peralta y Berenice Bravo Rubio (México: Instituto Nacional de Antropología e Historia, Escuela Nacional de Antropología e Historia, 2008), 131.

${ }^{70}$ En 1740 para la fiesta de la Natividad de Nuestra Señora se gastaba en los derechos parroquiales para una misa, flores, fuegos artificiales (como ruedas de pólvora y cohetes), comida y chocolate. Posteriormente, a partir de 1745 sólo alcanzaban las limosnas para los derechos del párroco, una comida y bebida de chocolate para los asistentes. AHBG, Santuario de Guadalupe, Serie Cofradías, caja 269, exp. 52, año ca. 1741, f. 2; AHBG, Santuario de Gua- 
era la fiesta grande o fiesta de los naturales, que por lo regular se celebraba en el mes de noviembre (el día 25) y tenía tanto fines religiosos como civiles; por último, el 12 de diciembre se conmemoraba con gran solemnidad el aniversario de la aparición de la virgen del Tepeyac al indio Juan Diego. Las celebraciones se llevaban a cabo con las limosnas recolectadas por el mayordomo. A partir de 1683 se acordó que cada mes se debía efectuar una misa cantada por el aumento y el progreso de la institución en la antigua iglesia de los indios. ${ }^{71}$ De tal manera la cofradía se convirtió a nivel local en una manifestación de convivencia y de colaboración para la celebración de las festividades. ${ }^{72}$

Por otro lado, la cofradía se preocupaba por cada uno de sus integrantes, en especial por los que estaban enfermos; se le pedía al rector, mayordomo y diputados que acudieran a visitarlos, asistirlos y consolarlos; además los invitaban a que no se descuidaran y a que recibieran los sacramentos de la penitencia, comunión y extremaunción. Cuando les llevaban el viático ${ }^{73} \mathrm{O}$ un socio moría, los cofrades debían alumbrar el camino con velas. ${ }^{74} \mathrm{La}$ cofradía se preocupaba por la salvación del alma de los socios tal como lo estipulaba la cláusula quinta de su constitución: "que para que se consiga el fin principal de fundar la dicha cofradía para que las almas de los difuntos hermanos de ella sean ayudados de sus sufragios mediante los cuales y meritos de Nuestro Señor Jesucristo salgan de las penas del purgatorio y gocen de la vida eterna". ${ }^{75}$

En el mes de noviembre uno de los días de la octava de difuntos (por lo general el día dos), la cofradía debía mandar decir una misa mayor de requiem ${ }^{76}$ por los cofrades muertos, además de acudir a visitarlos a sus tumbas con cera, ofrendas y responsos. Hacia 1760, cuando un socio fallecía, la institución se comprometía a pagar tres pesos y un real para ayudar con su funeral y tres misas rezadas; además de regresarle lo que hubiese

dalupe, Serie Cofradías, caja 269, exp. 78, año 1745, f. 3, y AHBG, Santuario de Guadalupe, Serie Cofradías, caja 270, exp. 59, año 1749, f. 3.

${ }^{71}$ AHBg, Santuario de Guadalupe, Serie Cofradías, caja 378, exp. 12, año ca. 1740, f. 1.

${ }^{72}$ Gómez Pabellón, "El sistema de cargos en Mesoamérica”, 61.

${ }^{73}$ Era la comunión que se llevaba a un moribundo o a una persona enferma de gravedad. Tomás Parra Sánchez, Diccionario de liturgia (México: San Pablo, 1996), 169.

${ }^{74}$ AHBg, Secretaría Capitular, Serie Cofradías, caja 357, exp. 5, año 1760-1762, f. 19.

75 AHвg, Secretaría Capitular, Serie Cofradías, caja 357, exp. 5, año 1760-1762, f. 17.

${ }^{76}$ Vocablo del latín que significa descanso. Primera palabra de la antífona con la que comenzaba la llamada misa de difuntos, de donde se le dio el nombre de misa de requiem. Parra Sánchez, Diccionario de liturgia, 147. 
dado durante su primero o segundo año como cofrade, los hermanos debían acompañar al cuerpo del cofrade difunto con luces (velas) a la hora de su entierro. ${ }^{77}$ La Cofradía de Nuestra Señora de Guadalupe, como todas las que se fundaron en el centro de la Nueva España, cumplieron con propósitos asistenciales, proporcionando ayuda espiritual a los socios en momentos de enfermedad y apoyo material cuando el integrante fallecía, facilitando lo necesario para su entierro. Esta asociación subsistió como institución eclesiástica autónoma hasta los últimos años del siglo XIX; en este tiempo la institución contaba con pocos integrantes y no tenía grandes ingresos económicos, por lo que la congregación de españoles la agregó a sí misma cuando se convirtió en archicofradía al finalizar el mismo siglo.

\section{RELACIÓN CORPORATIVA ENTRE LAS TRES CONGREGACIONES DE INDIOS FUNDADAS EN EL SANTUARIO DEL TEPEYAC}

Recordemos que, además de la cofradía dedicada a la virgen de Guadalupe, existieron en el santuario del Tepeyac otras dos asociaciones constituidas también por indios; éstas eran la del Santo Entierro de Cristo y la de Jesús de las Caídas, posiblemente creadas a finales del siglo xvir. Delfina López Sarrelangue analizó un documento de la segunda mitad del siglo XVIII, y afirma que las tres asociaciones compartían la misma administración. ${ }^{78}$ Cabe resaltar que es en este tiempo cuando alcanzaron su máximo esplendor como organizaciones corporativas. De acuerdo con la documentación analizada, solamente existe información precisa de la cofradía dedicada a la Guadalupana con base en la validación de su constitución en 1679 por las autoridades eclesiásticas y civiles; de las otras dos no se encontraron datos concretos sobre su fundación como cofradías, solamente se hallaron datos aislados sobre las actividades que realizaban a lo largo del año litúrgico.

Tanto la asociación del Santo Entierro de Cristo como la de Jesús de las Caídas mandaban decir una misa cantada cada mes en el santuario con la limosna de 18 reales, por el aumento y progreso de cada una de las cofradías; además cada año las dos celebraban la festividad de la Santa Cruz en el mes de mayo con una misa, flores, cera, plata, fuegos artificiales (ruedas y cohetes),

77 AHBg, Secretaría Capitular, Serie Cofradías, caja 357, exp. 5, año 1760-1762, f. 33.

${ }^{78}$ López Sarrelangue, Una villa mexicana en el siglo XVIII, 257. 
danzas (chirimiteros) y almuerzo para los asistentes. ${ }^{79}$ La Cofradía de Jesús de las Caídas celebraba la fiesta de una imagen de Jesús en el mes de octubre con una misa solemne; ${ }^{80}$ en 1740 se llevó a cabo con gran esplendor. Adornaron con flores, cera y plata; quemaron fuegos artificiales; hubo danzantes, así como música, y dieron de beber chocolate a los invitados. ${ }^{81}$

Las celebraciones propias de la Cofradía del Santo Entierro de Cristo fueron precisamente los oficios para conmemorar la Semana Santa. Los miembros de la institución celebraban la Cuaresma: una procesión el Domingo de Ramos, otra procesión el Jueves Santo y posteriormente la adoración del Santísimo Sacramento en el monumento ${ }^{82}$ (reservado en el altar mayor), para lo cual adornaban el interior del santuario con naranjas y velas; el Viernes Santo se llevaba a cabo una procesión y una comida; el sábado santo tenía lugar la ceremonia del descendimiento; ${ }^{83}$ el Domingo de Resurrección se celebraba con una procesión, y posteriormente celebraban solemnemente la Pascua. Por otro lado, en el mes de noviembre se oficiaba una misa de requiem por los difuntos de la institución, al igual que la cofradía guadalupana. Los documentos para la reconstrucción de la historia de esta cofradía son escasos y comienzan a surgir a partir del año de 1739 en el Archivo Histórico de la Basílica de Guadalupe.

Los egresos de la asociación iban desde las palmas para el Domingo de Ramos, una arroba ${ }^{84}$ de cera de castilla (que servía para todas las celebraciones de la corporación a lo largo del año), flores y naranjas que se compraban para el monumento del Jueves Santo; además cada año se compraba una arroba de colación, sin olvidar lo que se gastaba para las comidas, almuerzos y los derechos parroquiales para oficiar las celebraciones. Los ingresos para solventar todos los gastos provenían en su mayoría de las limosnas y cuotas que efectuaban los socios periódicamente. Hacia 1749 el rector, el mayordomo -don Julián Antonio- y los diputados aportaban una cantidad mayor

${ }^{79}$ AHBg, Santuario de Guadalupe, Serie Cofradías, caja 269, exp. 52, año ca. 1741, f. 2.

${ }^{80}$ López Sarrelangue, Una villa mexicana en el siglo XVIII, 258.

${ }^{81}$ AHBg, Santuario de Guadalupe, Serie Cofradías, caja 269, exp. 52, año ca. 1741, f. 2.

${ }^{82}$ Era el túmulo, altar o aparato, que el Jueves Santo se edificaba en las iglesias, donde se colocaba en una arquita a modo de sepulcro, la segunda hostia que se consagraba en la misa de aquel día, para reservarla hasta los oficios del Viernes Santo, se adornaba con velas, flores y frutas (principalmente naranjas). Véase Dorothy Tanck de Estrada, Pueblos de indios y educación en el México colonial 1750-1821 (México: El Colegio de México, 1999), 313.

${ }^{83}$ Delfina López Sarrelangue, Una villa mexicana en el siglo XVIII, 258.

${ }^{84}$ Medida de peso de 25 libras de 16 onzas cada una, equivalentes a 11 k y 502 g. Real Academia Española, Diccionario de autoridades, 1:415. 
para solventar los gastos de la cofradía. ${ }^{85} \mathrm{Al}$ igual que en la Cofradía de Nuestra Señora de Guadalupe, los integrantes de la mesa directiva pedían licencia al arzobispado de México para recolectar limosnas por los barrios, pueblos de la jurisdicción del pueblo de Guadalupe y de la ciudad de México.

En 1739 la Cofradía del Santo Entierro de Cristo tenía como rector de la institución a don Salvador Manuel y de mayordomo a don Juan de los Ángeles, quienes rindieron cuentas de las limosnas al cura interino don José de Riaño, estando presentes los oficiales de la república de indios del pueblo de Guadalupe: el gobernador, don Antonio de San Juan; el alcalde presidente, don Manuel de la Trinidad; el alcalde ordinario, don Juan Claudio. En ese mismo año la institución contaba con 172 socios de los cuales dos se habían dado de baja; del pueblo de Guadalupe asistían 23 individuos; del barrio de Ateposco, 18; del barrio de Tlatilulco, 15; del pueblo de Santiago Atzacualco, 30; del pueblo de San Juan Ixhuatepec, 36; del pueblo de San Pedro Zacatenco, 19; y del pueblo de Santa Isabel Tola, 30. Como se puede apreciar, la parcialidad de San Juan Ixhuatepec era la que aportaba más integrantes a la asociación. ${ }^{86}$

En 1760 las autoridades de la Cofradía de Nuestra Señora de Guadalupe iniciaron la construcción de un altar colateral ${ }^{87}$ en la iglesia de los indios, para la imagen del Santo Entierro de Cristo, con las limosnas de la asociación guadalupana. ${ }^{88}$ Este dato apunta que, para la segunda mitad del siglo XVIII, la asociación del Santo Entierro era ayudada con limosnas por la cofradía que tenía por patrona a la virgen de Guadalupe. Es preciso señalar que en este tiempo, con el cambio coyuntural de la dinastía de los Borbones (en la monarquía española), se da un mayor control por parte del Estado y de la Iglesia sobre la legalidad de las formas corporativas que se fundaron en la época novohispana, sobre todo en las cofradías, porque había más de 900 en el territorio de la Nueva España y muchas de ellas carecían de los requisitos que las validaran como tales, razón por la cual las autoridades eclesiásticas intentaron reorganizarlas eliminando casi la mitad y congregando o refundando las que tuvieran recursos económicos y prestigio social. ${ }^{89}$

${ }^{85}$ AHBG, Santuario de Guadalupe, Serie Cofradías, caja 270, exp. 59, año 1749, f. 4.

${ }^{86}$ AHBG, Santuario de Guadalupe, Serie Cofradías, caja 280, exp. 86, año 1739, f. 8.

${ }^{87}$ Eran las capillas o altares que se encontraban dentro de las iglesias, casi por lo regular a los costados del altar mayor.

${ }^{88}$ AHBg, Secretaría Capitular, Serie Cofradías, caja 357, exp. 5, año 1760-1762, f. 34.

${ }^{89}$ José Antonio Cruz Rangel, "Las cofradías indígenas en el siglo XVIII, un sistema colonial de poder, resistencia y exacción. El caso de Chimalhuacán Atenco”, Dimensión Antro- 
En el último tercio del siglo xviII, el arzobispo de México Alonso Núñez de Haro y Peralta (quien gobernó la curia episcopal de 1771-1800) se dio a la tarea de ordenar la multitud de corporaciones novohispanas existentes en el territorio del arzobispado antes de desaparecerlas; para el prelado era relevante que los fieles laicos, sobre todo los indios, mantuvieran el fervor a la Iglesia y al culto divino, además de que las corporaciones eran bastante útiles para el sostenimiento de las parroquias, de los curas y de las devociones. ${ }^{90}$ Muchas de las cofradías fundadas con anterioridad tenían la licencia del ordinario para establecerse y otras carecían de dicho documento.

Para Núñez de Haro y Peralta existían tres tipos de cofradías: las de retribución temporal (aquellas que proporcionaban a sus integrantes beneficios a partir de sus aportaciones), las que no contaban con retribución (encaminadas a fortalecer el culto y la devoción) y las espirituales (en ellas sus integrantes podían obtener apoyo en misas e indulgencias, pero sin beneficios materiales). Carolina Aguilar García afirma que para el arzobispo ilustrado los criterios étnicos para catalogar a las cofradías ya no eran necesarios, debido a la reorganización parroquial que se llevó a cabo durante el siglo XVIII, ${ }^{91}$ que pretendía que todos los fieles permanecieran en su propia parroquia para todo acto litúrgico y ceremonial. ${ }^{22}$

A partir del año de 1760 las tres asociaciones compartían tanto a la misma feligresía como a la misma mesa directiva, seguramente por la falta de socios y de recursos económicos, y porque las actividades que realizaban a lo largo del año litúrgico eran semejantes y complementarias. Quizá las asociaciones del Santo Entierro de Cristo y la de Jesús de las Caídas funcionaron como cofradías autónomas en el ámbito económico, hasta la segunda mitad del siglo XVIII y a partir de ese momento solamente sobrevivieron con la finalidad de llevar a cabo los oficios litúrgicos para recordar la pasión, muerte y resurrección de Jesús en la Semana Santa, sin la necesidad de contar con la autorización de un obispo y la validación de su constitución por un representante real para desarrollar sus actividades religiosas, o por el prestigio del lugar donde se encontraban establecidas, que era en el complejo arquitectónico de la Insigne, Real y Colegiata de Guadalupe, además

pológica (Escuela Nacional de Antropología e Historia, México), v. 36, año 13 (enero-abril 2006), 94.

${ }^{90}$ Aguilar García, La reforma arzobispal, 243.

${ }^{91}$ Aguilar García, La reforma arzobispal, 244.

${ }^{92}$ García Ayluardo, Desencuentros con la tradición, 210. 
de que continuaron con sus actividades pese a las reformas de los arzobispos ilustrados.

Por otro lado, de acuerdo con la clasificación de Alonso de Haro y Peralta, la Cofradía de Nuestra Señora de Guadalupe, la Cofradía del Santo Entierro de Cristo y la Cofradía de Jesús de las Caídas, integradas las tres por indios, eran de retribución temporal ya que seguían otorgando beneficios materiales a sus socios a partir de sus aportaciones económicas. Cabe señalar que, pese a los intentos de reorganizar las formas del corporativismo novohispano, por parte de las autoridades civiles y eclesiásticas de finales del siglo XviII, instituciones como las cofradías conservaron su naturaleza multifacética (social, económica y política) como elementos participativos y decisivos en la construcción, desarrollo y permanencia de la Iglesia novohispana. ${ }^{93}$ Las cofradías de indios que se establecieron en el Santuario de Guadalupe (llamado así en los documentos hasta 1749) lograron agrupar a la población nativa alrededor de la fe católica y hacer del corporativismo eclesiástico, el mecanismo que logró dar cohesión a una sociedad heterogénea donde los actos públicos giraban dentro de la dinámica colectiva y no desde el plano individual.

\section{Conclusiones}

El estudio de las corporaciones eclesiásticas (como las cofradías, las congregaciones, las hermandades o devociones y las mayordomías) revela el desarrollo de las prácticas religiosas y las creencias que se propagaron durante el periodo novohispano en las comunidades de indios y de españoles, donde se crearon lazos de hermandad y solidaridad, así como relaciones económicas, de parentesco y de prestigio social, además de que los distintos actos como las misas, las procesiones, las fiestas, las comidas y los bailes captaron la atención de todos los novohispanos.

Las congregaciones guadalupanas que se establecieron en el santuario del Tepeyac como organizaciones corporativas ayudaron a consolidar la devoción a la virgen de Guadalupe entre los indios y los españoles durante el siglo XVII. Gracias a la labor de estas instituciones, se desarrolló entre la sociedad un culto formal a la virgen María en su advocación de Guadalupe,

${ }^{93}$ García Ayluardo, Desencuentros con la tradición, 27. 
primero a nivel local o regional y posteriormente por todo el territorio del virreinato de la Nueva España y más allá del Atlántico.

Dorothy Tanck de Estrada divide a las cofradías de indios para su estudio en dos tipos: a) las cofradías eclesiásticas, y b) las cofradías de república o del pueblo. En las primeras, el sacerdote vigilaba sus actividades y los cofrades participaban periódicamente en los actos encaminados al culto religioso; las segundas realizaban sus funciones sin la intervención del párroco, únicamente eran supervisadas de manera directa o indirecta por las autoridades de la república de indios; estas asociaciones tenían una dotación de ganado o de tierra cuyo producto servía para las misas de todo un año. ${ }^{94}$ De acuerdo con lo anterior, podemos ubicar a la Cofradía de Nuestra Señora de Guadalupe, fundada por naturales en su santuario en el siglo XVII, como eclesiástica, pues todas sus funciones eran supervisadas por el vicario, el párroco, el canónigo magistral y el juez provisor de indios y chinos del Arzobispado de México, además de servir como instrumento para aumentar y fomentar el culto católico de manera colectiva entre los naturales del pueblo de Guadalupe.

Finalmente, los aportes del presente artículo son los siguientes: la cofradía eclesiástica de la virgen de Guadalupe fundada por indios, en el aspecto legal, desarrolló sus funciones como institución dentro del marco de la legitimidad de acuerdo con la legislación eclesiástica y civil al momento de su fundación, después de que el vicario de la ermita del Tepeyac, don Alonso de Hita, validara la formación de la asociación. Una vez que los socios redactaron sus constituciones fueron llevadas al juez provisor de los naturales, don Lope Cornejo de Contreras, para que las revisara y confirmara el 27 de febrero de 1679 con la aprobación del ordinario, el arzobispo de México y virrey de la Nueva España, don fray Payo Enríquez de Rivera, la cofradía quedó establecida en la iglesia de los indios dentro del territorio del santuario del Tepeyac.

En el aspecto administrativo, la cofradía contó con una mesa directiva compuesta por ocho oficiales, un rector, un mayordomo y seis diputados que tenían la responsabilidad de llevar a cabo la organización al interior

${ }^{94}$ Dorothy Thanck de Estrada, "Los bienes y la organización de las cofradías en los pueblos de indios del México colonial: debate entre el Estado y la Iglesia”, en La Iglesia y sus bienes: de la amortización a la nacionalización, coordinación de María del Pilar Martínez López-Cano y Gisela von Wobeser (México: Universidad Nacional Autónoma de México, 2004), 337. 
de la asociación, además de solventar los gastos, por lo que no cualquier cofrade podía acceder a ocupar los cargos más representativos; los funcionarios debían contar con prestigio social y económico dentro de la comunidad. De su excelente capacidad para administrar y dirigir a la corporación religiosa dependía su posible participación como oficiales de la república de indios del pueblo de Guadalupe; de manera que a partir de la convivencia rutinaria entre los socios de la cofradía mediante los actos de piedad y la realización de las festividades se entretejían relaciones de poder dentro de la élite indígena que favorecían políticamente a un individuo miembro de una colectividad.

En el aspecto económico, los ingresos de la cofradía guadalupana solamente estaban constituidos por las limosnas que se demandaban por la jurisdicción del Arzobispado de México. Los egresos de la corporación iban desde las funciones del párroco, las flores, la cera, los gastos para la reparación de la iglesia de indios y la casa de novenas; el pago de los cantores para el mayor lucimiento en los oficios litúrgicos, la ayuda para las defunciones de los socios, hasta la realización de las fiestas; lo que se tenía que comprar para las comidas tanto para los cofrades como para las autoridades civiles; lo que se pagaba para las danzas y también para los fuegos artificiales, actos que a través de sus representaciones y comportamientos formaban parte de la mentalidad colectiva de la sociedad novohispana.

En el aspecto social, durante el año litúrgico la cofradía celebraba tres solemnidades: una el 8 de septiembre, otra el 25 de noviembre, y una más el 12 de diciembre, además de que se llevaban a cabo varios oficios litúrgicos como procesiones, misas, entierros a las que los socios tenían la obligación de asistir, la labor caritativa y de beneficencia en la asociación también se consolidó, los integrantes de la mesa directiva tenían la obligación de visitar y asistir a sus hermanos enfermos invitándolos a recibir los sacramentos de la confesión, la comunión, y la extremaunción, además de acudir a sus entierros de manera solemne; estos actos daban cohesión e identidad entre los miembros de la comunidad.

Finalmente en la relación corporativa entre las tres asociaciones establecidas por los indios en el santuario del Tepeyac a finales del siglo XVII, las fuentes hacen referencia a tres cofradías: la de la virgen de Guadalupe, la del Santo Entierro de Cristo y la de Jesús de las Caídas, que compartían tanto a la misma mesa directiva y a la feligresía durante la segunda mitad del siglo XVIII, las tres instituciones se complementaban para realizar las actividades religiosas a lo largo del año litúrgico, además de que estuvieron 
dedicadas a dos de los personajes más representativos del catolicismo novohispano: Jesucristo y la virgen María. Pese a las reformas que efectuaron los arzobispos ilustrados a las cofradías en los últimos años del periodo novohispano, estas asociaciones persistieron, con la finalidad de congregar, instruir y preservar las manifestaciones del culto católico en los indios en torno al corporativismo eclesiástico.

No todo está escrito en la presente investigación; es por ello que hace falta un estudio completo de la Congregación de Nuestra Señora de Guadalupe, fundada por los españoles en el santuario del Tepeyac, así como de otras asociaciones que se fundaron en otras parroquias de la ciudad de México y de la Nueva España, que estuvieron bajo la protección de la virgen de Guadalupe. Si bien existe una gran cantidad de estudios historiográficos que abordan como problemática central el estudio de las cofradías, hacen falta investigaciones sobre las políticas de los arzobispos de la segunda mitad del siglo XVIII y la manera en la que estas instituciones sobrevivieron a las reformas, a finales del periodo colonial.

Para terminar considero que el profesional de la historia no debe comprender la mentalidad de la época novohispana sin dejar de estudiar a fondo el fenómeno del corporativismo eclesiástico, como el mecanismo que logró dar cohesión a la sociedad en los ámbitos político, económico y social, a partir del análisis de los actos públicos y religiosos que se realizaban al interior de las cofradías, las congregaciones, las hermandades o devociones y las mayordomías, que giraban dentro de la dinámica colectiva y no desde el plano individual. Se debe tomar en cuenta que a partir de la segunda mitad del siglo XVIII, con los reformadores ilustrados se trató de controlar la formación de las cofradías que eran centros autónomos de lealtades locales que estorbaban a las políticas regalistas de la Corona española.

\section{FUENTES}

Fuentes primarias

Archivo General de la Nación (AGN)

Indiferente Virreinal, Cofradías y Archicofradías, caja 2692, exp. 12, año 1679, f. 1. Indiferente Virreinal, General de Parte, caja 2571, exp. 024, año 1774, f. 3.

Cofradías y Archicofradías, caja 4762, exp. 2, año 1778, f. 1.

Clero Secular y Regular, contenedor 44, v. 112, exp. 1, año 1801, f. 25. 
Archivo Histórico de la Basílica de Guadalupe (АнвG)

Secretaría Capitular, Serie Cofradías, caja 340, exp. 71, año 1678, f. 1.

Santuario de Guadalupe, Serie Cofradías:

caja 391, exp. 33, año ca. 1705, f. 1;

caja 280 , exp. 86 , año 1739 , f. 8 ;

caja 378 , exp. 12 , año ca. 1740 , f. 1 ;

caja 269, exp. 52, año ca. 1741 , f. 4 ;

caja 269 , exp. 78 , año 1745 , f. 4 ;

caja 270 , exp. 59 , año 1749 , f. 4 ;

caja 357, exp. 3, año ca. 1755, f. 1;

caja 357, exp. 5, año 1760-1762, f. 32;

caja 346, exp. 9, año 1772 , f. 1 ;

caja 356, exp. 9, año ca. 1777, f. 3;

caja 346, exp. 30, año 1778, f. 1;

caja 356 , exp. 8 , año ca. 1780 , f. 2 ;

caja 403, exp. 18, año 1786, f. 2.

Fuentes secundarias

Álbum de la Coronación de la Santísima Virgen de Guadalupe. México: Imprenta El Tiempo de Victoriano Agüeros, 1895.

Aguilar García, Carolina Yveth. "La reforma arzobispal y monárquica de cofradías y otras asociaciones seglares en Ciudad de México y pueblos circunvecinos, 1750-1808." Tesis doctoral. México: Universidad Nacional Autónoma de México, 2019.

Arteche B., Gonzalo. El Código de Derecho Canónico. Traducido y comentado. V. 1. Santiago de Chile: Imprenta San Francisco, 1944.

Bazarte Martínez, Alicia. Las cofradías de españoles en la ciudad de México (15261860). México: Universidad Autónoma Metropolitana, Azcapotzalco, 1989.

Bechtloff, Dagmar. Las cofradías en Michoacán durante la época de la Colonia: la religión y su relación política y económica en una sociedad intercultural. México: El Colegio de Michoacán/El Colegio Mexiquense, 1996.

Cruz Rangel, José Antonio. "Las cofradías indígenas en el siglo XviII, un sistema colonial de poder, resistencia y exacción. El caso de Chimalhuacán Atenco." Dimensión Antropológica (Escuela Nacional de Antropología e Historia, México) 36, año 13 (enero-abril 2006): 93-132.

Donoso, Justo. Instituciones de derecho canónico americano. V. 3. París: Librería de la Rosa y Bouret, 1852. 
Escalada, Xavier. Enciclopedia Guadalupana. Temática, histórica y onomástica. V. I. México: Dos Colinas Vaticano y Tepeyac, 1995.

Fernández, Martha. La imagen del templo de Jerusalén en la Nueva España. México: Universidad Nacional Autónoma de México, 2003.

García Ayluardo, Clara. Desencuentros con la tradición. Los fieles y la desaparición de las cofradías de la ciudad de México en el siglo XVIII. México: Fondo de Cultura Económica/Consejo Nacional para la Cultura y las Artes, 2015.

García Ayluardo, Clara. "Para escribir una historia del cristianismo en México: las cofradías novohispanas y sus fuentes." En De sendas, brechas y atajos. Contexto y crítica a las fuentes eclesiásticas; siglos XVI-XVIII, 125-146. Coordinación de Doris Bieñko de Peralta y Berenice Bravo Rubio. México: Instituto Nacional de Antropología e Historia, Escuela Nacional de Antropología e Historia, 2008.

García Gutiérrez, Jesús. Efemérides guadalupanas publicadas con motivo de la celebración del IV Centenario de las apariciones de la Santísima Virgen de Guadalupe. México: Antigua Imprenta de Murguía, 1931.

Gómez Pabellón, Eloy. "El sistema de cargos en Mesoamérica: de fundación piadosa a institución político-religiosa.” Revista Española de Antropología Americana (Ediciones Complutense), v. 46 (2016): 49-70.

Lafaye, Jacques. Quetzalcóatl y Guadalupe. La formación de la conciencia nacional en México. Traducción de Ida Vitale y Fulgencio López Vidarte. 1a. reimp. México: Fondo de Cultura Económica, 1991.

Lavrin, Asunción. "La Congregación de San Pedro. Una cofradía urbana del México colonial 1604-1730.” Historia Mexicana (El Colegio de México) xxıx, n. 4 (abril-junio 1980): 562-601.

López Sarrelangue, Delfina. Una villa mexicana en el siglo XVIII: Nuestra Señora de Guadalupe, 2a. ed. México: Universidad Nacional Autónoma de México, Instituto de Investigaciones Históricas/Miguel Ángel Porrúa, 2005.

Mancuso, Lara. Cofradías mineras: religiosidad popular en México y el Brasil. Siglo XVIII. México: El Colegio de México, 2007.

Martínez Huerta, Iván. "Los estrenos de una casa. Los traslados y fiestas en Guadalupe.” Boletín Guadalupano. Información del Tepeyac para los Pueblos de México (Publicación mensual gratuita de la Basílica de Guadalupe, México), n. 105, año IX (septiembre 2009): 22-24.

Manzano Manzano, Juan. Recopilación de leyes de los Reynos de Indias, v. I. Prólogo de Ramón Méndez y Pidal. Madrid: Ediciones Cultura Hispánica, 1973.

Mayer, Alicia. "Las corporaciones guadalupanas: centros de integración 'universal' del catolicismo y fuentes de honorabilidad y prestigio.” En Formaciones religiosas en la América colonial, coordinación de María Alba Pastor y Alicia Mayer, 179-201. México: Universidad Nacional Autónoma de México, Facultad de Filosofía y Letras, 2000. 
Miranda Godínez, Francisco. Dos cultos fundantes: los Remedios y Guadalupe (15211649). Historia documental. México: El Colegio de México, 2001.

Montes de Oca, Luis T. Las tres primeras ermitas guadalupanas del Tepeyac: algunas conjeturas acerca de las ruinas arqueológicas del siglo XVI, encontradas en la sacristía de la Parroquia Archipresbitral de Santa María de Guadalupe. México: Imprenta Labor Mix, 1937.

Ortiz Rodea, Juan Javier. "La Cofradía de Nuestra Señora de Guadalupe fundada en el Santuario del Tepeyac: 1678-1800. Una cofradía de indios en el mundo novohispano.” Tesis de licenciatura. Toluca, México: Universidad Autónoma del Estado de México, 2014.

Parra Sánchez, Tomás. Diccionario de liturgia. México: San Pablo, 1996.

Pastor, María Alba. “La organización corporativa de la sociedad novohispana.” En Formaciones religiosas en la América colonial, coordinación de María Alba Pastor y Alicia Mayer, 81-140. México: Universidad Nacional Autónoma de México, Facultad de Filosofía y Letras, 2000.

Pérez Puente, Leticia, et al. "Primer y segundo concilios.” En Concilios provinciales mexicanos. Época colonial, coordinación de María del Pilar Martínez López-Cano, versión en CD-ROM. México: Universidad Nacional Autónoma de México, Instituto de Investigaciones Históricas, 2004.

Real Academia Española. Diccionario de autoridades. Serie Biblioteca Romana Hispánica. 2 v. Madrid: Gredos, 1990.

Schwaller, John F. "Los miembros fundadores de la Congregación de San Pedro, México, 1557." En Cofradías, capellanías y obras pías en la América colonial, coordinación de María del Pilar Martínez López-Cano et al., 109-117. México: Universidad Nacional Autónoma de México, Instituto de Investigaciones Históricas, 1998.

Tanck de Estrada, Dorothy. "Los bienes y la organización de las cofradías en los pueblos de indios del México colonial debate entre el Estado y la Iglesia.” En La Iglesia y sus bienes: de la amortización a la nacionalización, coordinación de María del Pilar Martínez López-Cano y Gisela von Wobeser, 335-355. México: Universidad Nacional Autónoma de México, 2004.

Tanck de Estrada, Dorothy. Pueblos de indios y educación en el México colonial 17501821. México: El Colegio de México, 1999.

Valero de García Lascuráin, Ana Rita. La Archicofradía Universal de Nuestra Señora de Guadalupe. Pasado y presente. México: Insigne y Nacional Basílica de Guadalupe, 2002.

Watson Marrón, Gustavo. "Los templos del Tepeyac ayer y hoy.” En Memoria del Congreso Guadalupano. "Mucho quiero, muchísimo deseo que aquí me levanten mi templo" 8, 9 y 10 de octubre de 2001, 27-55. México: Publicaciones de la Basílica 
de Guadalupe; Instituto de Estudios Teológicos e Históricos Guadalupanos, 2002.

Watson Marrón, Gustavo. "Significado del nombre 'Insigne y Nacional Basílica de Guadalupe (2da. Parte)'.” Boletín Guadalupano. Información del Tepeyac para los Pueblos de México (Publicación mensual gratuita de la Basílica de Guadalupe, México), n. 124, año xi (julio 2011): 34-35.

Watson Marrón, Gustavo. “La Parroquia Antigua de Indios.” Boletín Guadalupano. Información del Tepeyac para los Pueblos de México (Publicación mensual gratuita de la Basílica de Guadalupe, México), n. 126, año xi (septiembre 2011): 33-37.

Watson Marrón, Gustavo. El templo que unió a Nueva España. Historia del santuario y Colegiata de Guadalupe extramuros de México en el siglo XVIII. México: Basílica de Guadalupe/Miguel Ángel Porrúa/Seminario Conciliar de México, 2012. 
